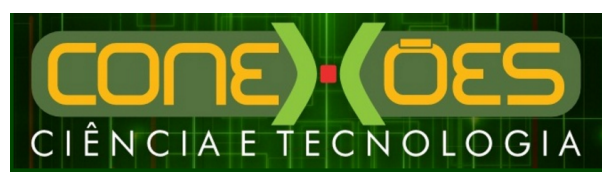

\title{
DESENVOLVIMENTO, CARACTERIZAÇÃO E AVALIAÇÃO SENSORIAL DE SALGADINHO DE FRANGO SEM GLÚTEN
}

\author{
Samuel Carneiro de Barcelos ${ }^{1}$, Denise Souza de Freitas $^{2}$, \\ Liviany Sampaio da Silva Chacon ${ }^{2}$, Thallyne de Brito Alves ${ }^{2}$, \\ Alexsandra Araújo de Moura ${ }^{2}$, Daniele Maria Alves TeiXeira Sán ${ }^{1}$, Leiliane Teles César ${ }^{2}$ \\ ${ }^{1}$ Instituto Federal de Ciência e Tecnologia do Ceará - IFCE, Campus Limoeiro do Norte \\ ${ }^{2}$ Instituto Federal de Ciência e Tecnologia do Ceará - IFCE, Campus Sobral \\ <s.c.barcelos.ifce@gmail.com>, <denise-souza-freitas@ hotmail.com> \\ <liviany_sampaio@hotmail.com>.<thallyne_alves@hotmail.com>. \\ <alearaujo.m@gmail.com>.<daneileteixeira@gmail.com>.<leilianeteles@ifce.edu.br>
}

DOI: 10.21439/conexoes.v11i6.1041

\begin{abstract}
Resumo. A formação do glúten ocorre quando determinadas farinhas é misturada com água por processo de ação mecânica. Alimentos contendo glúten ao serem consumidos por indivíduos isentos da enzima transglutaminase, causam várias reações adversas e esse transtorno é conhecido como doença celíaca. Dessa forma é interessante oferecer aos portadores dessa doença opções de alimentos nutritivos e saborosos. Objetivou-se neste trabalho desenvolver e avaliar as características físico-químicas e verificar a aceitação sensorial de um salgadinho de frango sem glúten (SFSG) indicado para pessoas celíacas. Trata-se de uma pesquisa experimental. Os SFSG foram submetidas às análises: umidade, lipídios, cinzas, proteínas, carboidratos e valor calórico total e microbiológicas: Coliformes a $45^{\circ} \mathrm{C}$, Staphylococcus aureus e Salmonella sp. As amostras foram submetidas ao teste de aceitação sensorial, seguindo o delineamento de blocos inteiramente casualizados, avaliando: aparência, textura, sabor e impressão global, utilizando escala hedônica de nove pontos. Os resultados da pesquisa demonstraram valores médios de 38,02\%, 11,21\%, 1,24\%, $7,14 \%, 42,37 \%$ para umidade, lipídios, cinzas, proteínas e carboidratos respectivamente; obtendo assim o valor calórico médio de 299,01 kcal. O SFSG apresentou-se dentro dos padrões microbiológicos preconizado pela legislação vigente, apresentando ausência de contaminação para Coliformes a $45^{\circ} \mathrm{C}$, S. aureus e Salmonella sp. O SFSG teve uma boa aceitação sensorial, obtendo médias de 7,41; 7,64; 7,64 e 7,56 para os atributos aparência, sabor, textura e aceitação global, respectivamente. Foi calculado o índice de aceitabilidade do produto obtendo-se o valor de $94,5 \%$. A partir dos resultados, conclui-se que é possível produzir um SFSG com boa aceitação sensorial.
\end{abstract}

Palavras-chaves: Celíacos, Restrição, Aceitação, Saúde.

\begin{abstract}
The formation of gluten occurs when certain flours are mixed with water by mechanical action. Foods containing gluten when consumed by individuals free of the enzyme transglutaminase, cause various adverse reactions and this disorder is known as celiac disease. In this way it is interesting to offer the patients of this disease options of nutritious and tasty foods. The objective of this work was to develop and evaluate the physico-chemical characteristics and to verify the sensorial acceptance of a gluten-free chicken salad (SFSG) indicated for celiac people. This is an experimental research. The SFSG were submitted to analyzes: moisture, lipids, ashes, proteins, carbohydrates and total and microbiological calorific values: Coliforms at $45^{\circ} \mathrm{C}$, Staphylococcus aureus and Salmonella sp. The samples were submitted to a sensorial acceptance test, following a completely randomized block design, evaluating: appearance, texture, taste and overall impression using a hedonic scale of nine points. The results showed average values of $38.02 \%, 11.21 \%, 1.24 \%, 7.14 \%, 42.37 \%$ for moisture, lipids, ashes, proteins and carbohydrates respectively; thus obtaining the average caloric value of $299.01 \mathrm{kcal}$. The SFSG was within the microbiological standards advocated by the current legislation, showing absence of contamination for Coliforms at $45^{\circ} \mathrm{C}$, S. aureus and textitSalmonella sp. The SFSG had a good sensory acceptance, obtaining means of 7.41; 7.64; 7.64 and 7.56 for the garlic appearance, taste, texture and overall acceptance, respectively. The product's acceptability index was calculated to obtain the value of $94.5 \%$. From the results, it is concluded that it is possible to produce a SFSG with good sensory acceptance.
\end{abstract}

Keywords: Celiacs. Restriction. Acceptance. Health.

\section{INTRODUÇÃO}

Atualmente, a preocupação com a saúde vem crescendo cada dia mais, os consumidores atuais, vem bus- cando produtos que sejam concomitantemente saborosos e nutritivos, aliado a um estilo de vida saudável. Com isso, torna-se necessário a busca por estratégias adequadas pela indústria alimentícia para o desenvolvi- 
mento de alimentos que tragam simultaneamente vantagens nutricionais aos consumidores e sirvam como prevenção de várias doenças, adicionalmente também devem ser práticos ao consumo, devido a agitação da vida cotidiana.

Existem diferentes grupos de pessoas que possuem algumas restrições alimentares. Um destes grupos são os que possuem sensibilidade e/ou intolerância ao glúten, que recebe o nome de doença celíaca (ACELBRA, 2015). A doença celíaca é uma enfermidade do intestino delgado, que pode se agravar pela ingestão de alimentos que contenha em sua constituição o glúten, proteína que está presente no trigo, que é a principal matéria prima para a fabricação de pães, bolos e outros alimentos, que estão presentes na alimentação cotidiana da população. Essa doença está se tornando cada vez mais comum, não só na população brasileira, mais também na população mundial. "Considerando a Europa e os EUA, a doença pode acometer uma de cada 100 a 200 pessoas (WOLFF; SEGAL; WOLFF, 2015).

A formação do glúten ocorre quando a farinha de trigo é misturada com água por processo de ação mecânica. A rede de glúten é formada quando a água começa a interagir com as proteínas insolúveis (glutenina e gliadina) da farinha de trigo. As gliadinas são proteínas de cadeia simples, extremamente pegajosas, que dão a consistência e viscosidade da massa, mais apresenta pouca resistência a extensão. Por sua vez as gluteninas apresentam a conformação de suas cadeias com ramificações, assim, apresentando a função de produzir extensibilidade a massa (NUNES et al., 2006).

O glúten permanece nos alimentos mesmo após serem adequadamente assados ou cozidos, portanto a dieta do celíaco deve ser feita de forma rigorosa, pois pode trazer maiores agravos à doença (ACELBRA, 2015). No tratamento da doença celíaca, o paciente deve aderir a uma dieta rigorosa, que leva a eliminação permanente de cereais e derivados que contenham glúten em sua constituição, como: trigo, centeio, cevada e aveia. As proteínas presentes nos alimentos que contêm o glúten não são iguais em todos os cereais: a hordeína na cevada, a secalina no centeio e avenina na aveia e a gliadina no trigo, mas todas são igualmente tóxicas ao portador da doença celíaca (SDEPANIAN, 2001).

No princípio os portadores da doença celíaca tiveram muita dificuldade em relação ao uso de produtos pouco habituais, começaram a aparecer reclamações acerca da falta de habilidade culinária e disponibilidade de tempo, para o preparo de alimentos que substituam os convencionais para o portador da doença. Dessa forma, não tinha uma oferta de produtos direcionados para o portador da doença celíaca que vinhesse substituir os convencionais, o que ocorria era a oferta de alimentos que não exigiam muita manipulação, como frutas, mingaus e ovos cozidos, o que acarretava a monotonia e desnutrição do portador da doença. Essa dieta não supria as necessidades nutricionais, debilitando o estado nutricional do mesmo (EGASHIRA et al., 1986).

Atualmente já é conhecido e disponível a utilização de alguns substitutos da farinha de trigo no preparo de alimentos para pessoas celíacas, apesar do seu custo ser mais elevado, infelizmente a disponibilidade desses produtos no mercado ainda não é auto suficiente em quantidade, qualidade e variedade. Para Paim, Schuck (2010) o custo da alimentação sem glúten no Brasil é em média $138 \%$ mais caro, tomando em consideração as principais categorias de alimentos com glúten (macarrão, pão, farinha, torrada, biscoito, bolo e cereais matinais), esses aumentos, ainda sofrem variações em diferentes capitais brasileiras, apresentando os valores mais elevados: Rio grande do Sul (RS) com $174 \%$ e os menores valores em Santa Catarina (SC) com 97\%. O comércio apesar do progresso constante, ainda não se encontra preparado para atender as necessidades alimentares de pessoas com intolerância ao glúten.

É comum utilizar farinha de milho, amido de milho, farinha de arroz, farinha de mandioca, fubá, fécula de batata, polvilho doce e polvilho azedo como substitutos da farinha de trigo na elaboração de alimentos sem glúten (Kotze, 2006). Atualmente existem pesquisas na área de desenvolvimento de novos produtos para celíacos, aplicando novos ingredientes no desenvolvimento de alimentos, como farinha de amaranto, quinoa, farinha de soja, massa de banana verde, farinha de sorgo, inhame, farinha de alfarroba, farinha de pupunha integral, farinha de fruta-pão, biomassa do feijão branco (AGUIAR; SOUZA, 2015; KIRINUS; COPETTI; OLIVEIRA, 2010; ZANDONADI, 2009; ALMEIDA; SÁ, 2009; FERREIRA et al., 2009; MONTEIRO, 2013; SILVA et al., 2014; ARAÚJO; MARQUES; SANTOS, 2014; OLIVEIRA; MARQUES, 2014; SANTOS et al., 2014a), respectivamente. Outras pesquisas associam os ingredientes substitutos da farinha de trigo com outros ingredientes que promovem benefícios a saúde (funcionais), podendo ser alegados como alimentos potencialmente funcionais, como a farinha de linhaça, farinha de chia e vitamina A (MACÊDO et al., 2014; PEREIRA et al., 2013; SANTOS et al., 2014b), respectivamente.

A farinha de arroz é um dos ingredientes mais conhecidos entre os celíacos como substitutos da farinha de trigo na elaboração de alimentos sem glúten. $\mathrm{O}$ arroz (Oryza sativa, L.) é um dos mais importantes alimentos 
da dieta humana, por ser fonte de calorias e proteínas, como também, por fazer parte da alimentação de dois terços da população mundial, aproximadamente 2,5 bilhões de pessoas (ROSELL; MARÇO, 2008). Sendo assim, por não conter glúten, o arroz acaba sendo uma boa opção para portadores da doença celíaca, além de apresentar maior digestibilidade, maior valor biológico e uma elevada taxa de eficiência protéica comparado a outros cereais (SEVERO; MORAES; RUIZ, 2010). Dentre os produtos preparadas com farinha de arroz a literatura descreve: bebidas, biscoitos, pudins, alimentos processados, molhos para salada e pães sem glúten (KADAN; ZIEGLER, 1989; MCCUE, 1997; KADAN et al., 2001), por não interferir na cor do produto final, por ser um alimento hipoalergênico e por possuir um sabor agradável (VIEIRA, 2008).

Para que um alimento tenha êxito, bons resultados de vendas no mercado, este depende de sua atuação junto ao seu nicho de mercado consumidor. A análise sensorial de produtos se constitui uma ferramenta de grande importâncias para o processo de desenvolvimento de novos produtos, bem como aqueles que passam por melhoramento de processos e mudança de ingredientes (RODRÍGUEZ; MEGÍAS; BAENA, 2003).

Os celíacos ainda tem muita dificuldade em se socializar em grupo (casamentos, coquetéis, festas de aniversário, confraternização, etc), por conta da dificuldade de alimentação, dos produtos alimentícios (receitas para festas) nessas comemorações rotineiramente são preparados quase exclusivamente alimentos com ingrediente que contém glúten na sua formulação.

O objetivo deste trabalho foi desenvolver e avaliar as características físico-químicas e a aceitação sensorial de um salgadinho de frango sem glúten direcionado para o consumo de pessoas celíacas.

\section{MATERIAIS E MÉTODOS}

\subsection{Materiais}

Gêneros alimentícios: todos os gêneros alimentícios utilizados para preparação do salgadinho de frango sem glúten foram adquiridos no comércio de Sobral-Ceará.

Todos os reagentes químicos utilizados foram de grau analítico.

\subsection{Produção do salgadinho}

O preparo e fritura do salgadinho de frango sem glúten foram realizados na planta piloto de panificação do Eixo Tecnológico de Produção Alimentícia do Instituto Federal de Educação, Ciência e Tecnologia do Ceará (IFCE) - Campus Sobral. Os ingredientes utilizados no preparo do recheio e da massa estão listados nas Tabelas 1 e 2 abaixo.

Tabela 1: Formulação do recheio do salgadinho de frango sem glúten.

\begin{tabular}{ccc}
\hline Ingredientes & Quantidade (g) & $\mathbf{( \% )}$ \\
\hline Cebola roxa & $100 \mathrm{~g}$ & 3,68 \\
Pimentão & $150 \mathrm{~g}$ & 5,52 \\
Alho & $15 \mathrm{~g}$ & 0,55 \\
Corante & $10 \mathrm{~g}$ & 0,36 \\
Peito de frango & $2000 \mathrm{~g}$ & 73,73 \\
Cheiro-verde & $150 \mathrm{~g}$ & 5,52 \\
Óleo de soja & $5 \mathrm{~g}$ & 0,18 \\
Extrato de tomate & $130 \mathrm{~g}$ & 4,79 \\
Sal & $7,5 \mathrm{~g}$ & 0,27 \\
Margarina & $145 \mathrm{~g}$ & 5,34 \\
\hline Total & $2712,5 \mathrm{~g}$ & $100 \%$ \\
\hline
\end{tabular}

Fonte: Autores

Tabela 2: Formulação da massa do salgadinho de frango sem glúten.

\begin{tabular}{ccc}
\hline Ingredientes & Quantidade (g) & $\mathbf{( \% )}$ \\
\hline Alho & $15 \mathrm{~g}$ & 1,76 \\
Óleo de soja & $5 \mathrm{~g}$ & 0,58 \\
Sal & $7,5 \mathrm{~g}$ & 0,88 \\
Batata inglesa & $500 \mathrm{~g}$ & 58,71 \\
Farinha de arroz & $324 \mathrm{~g}$ & 38,05 \\
\hline Total & $851,5 \mathrm{~g}$ & 100 \\
\hline
\end{tabular}

Fonte: Autores.

Preparo da massa: Após a pesagem dos ingredientes estes foram misturados manualmente até a obtenção de uma mistura homogênea. A massa foi levada ao fogo com o alho e óleo já dourados, acrescidos de mais óleo, sal e as batastas e submetidos a fervura, com adição gradual do caldo do frango em quantidade suficiente para formar uma massa modelável. Na sequência a mistura foi acrescida em uma panela com a farinha de arroz e após homogenizada, que resultou em uma massa de consistência firme e posteriormente a massa foi sovada.

Preparo do recheio: o peito de frango foi cortado em pedaços pequenos e levado ao fogo com alho e óleo já dourados, após foi refolgado e deixado cozinhar com pouca água. Logo após foi desfiado o frango e misturado com o extrato de tomate e temperos e levado ao fogo até ficar com uma consistência firme.

Após a massa e o recheio formulados, a massa foi aberta, adicionada o recheio e feito o molde do salgadinho. Logo após, foi armazenado sob congelamento em freezer no período de uma semana. E foi submetido a 
fritura no dia da realização da análise sensorial, acondicionado e armazenados em local arejado com baixa umidade até serem avaliadas.

Foi utilizado para a definição do tamanho da porção do salgadinho de frango sem glúten a RDC n 359 que define as Porções de Alimentos Embalados para Fins de Rotulagem Nutricional (ANVISA, 2003), que estabelece $40 \mathrm{~g}$ para produtos de panificação, salgados ou doces com recheio e/ou cobertura. A formulação rendeu 89 unidades, com uma porção de $40 \mathrm{~g}$.

Os salgadinhos de frango sem glúten foram elaborados conforme o fluxograma apresentado na Figura 1.

Figura 1: Fluxograma das etapas de fabricação do salgadinho de frango sem glúten.

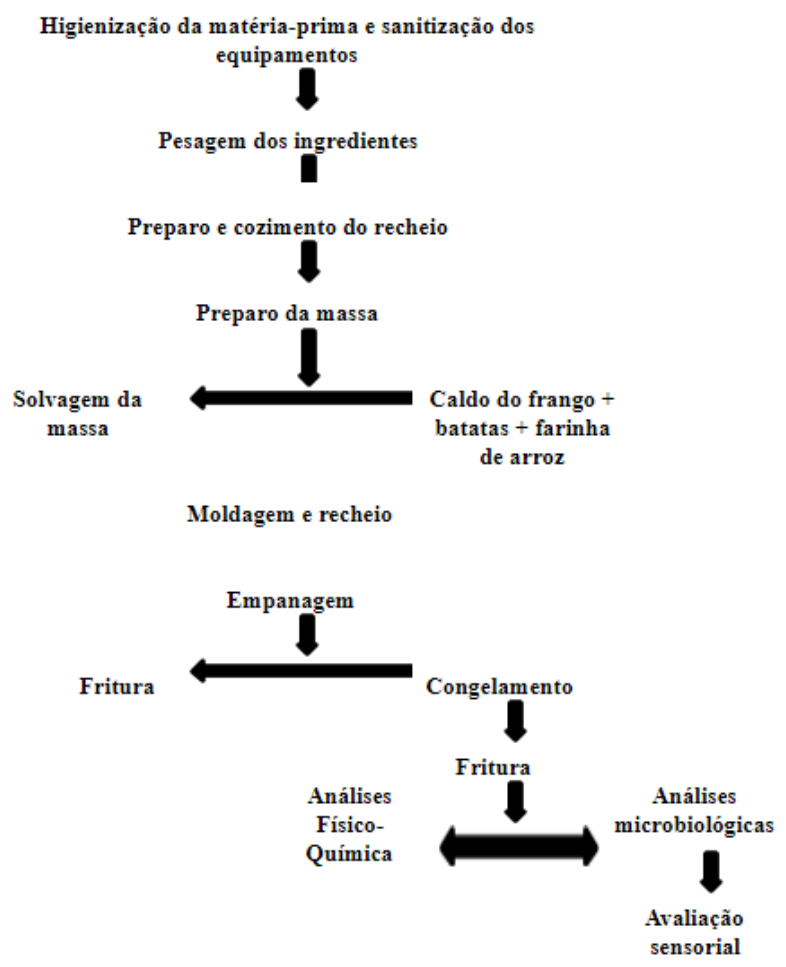

Fonte: Autores

\subsection{Composição centesimal}

Os salgadinhos de frango sem glúten foram submetidos às seguintes análises de composição, no dia do processamento, após fritura: Umidade; Cinzas; Proteínas; Lipídios; Carboidratos.

A avaliação dos salgadinhos de frango sem glúten foi determinada a partir das técnicas descritas pelo Instituto Adolfo Lutz (BRASIL, 2005). Todas as determinações foram realizadas em triplicata, conforme segue:
Umidade: determinação da umidade foi realizada por dessecagem direta a $55^{\circ} \mathrm{C}$ em estufa à vácuo; Cinzas: a determinação da matéria mineral foi realizada através de incineração do produto á temperatura de 500$550{ }^{\circ} \mathrm{C}$ em mufla; Proteínas: proteína foi determinada pelo método de Micro-Kjeldhal, usando o fator de 6,25 para conversão de nitrogênio em proteína; Lipídios: o método utilizado para determinação de lipídios foi extração de solventes utilizando Soxhlet; Carboidratos: os carboidratos foram calculados por diferença, sendo: $100 \%$ - (umidade $(\%)+$ cinzas $(\%)+$ proteína $(\%)+$ lipídios $(\%))=$ carboidratos totais, incluindo fibras. $\mathrm{O}$ valor calórico total kcal.100 $\mathrm{g}^{-1}$ do SFSG foi calculado pela soma dos resultados da multiplicação das porcentagens de proteínas, carboidratos e lipídeos pelos seus respectivos fatores de conversão (4; 4 e $9 \mathrm{kcal}_{\mathrm{g}}{ }^{-1}$ ), de acordo com a Equação 1:

$$
V C T^{(k c a l)}=(P \times 4)+(C \times 4)+(L \times 9),
$$

onde: VCT: Valor calórico total em kcal; P: Proteína; C: Carboidratos; e L: Lipídeos.

\subsection{Análises microbiológicas}

\section{Determinação dos parâmetros microbiológicos sa- nitários}

A determinação e pesquisa dos patógenos foram realizadas de acordo com a legislação brasileira que indica como padrão microbiológico para bolos, tortas e similares, doces ou salgados, com ou sem recheio e cobertura, estáveis à temperatura ambiente; pastéis, empadas, sanduíches quentes e outros salgados (ANVISA, 2001), após a fritura dos salgadinhos de frango sem glúten, as análises de Coliformes a $45^{\circ} \mathrm{C}$, Staphylococcus coagulase positiva e Salmonella sp. em $25 \mathrm{~g}$.

Para a determinação e pesquisa dos patógenos foi utilizado as técnicas descritas pela Instrução Normativa $n^{\circ} 62$ de 26 de agosto de 2003 (BRASIL, 2003), para as análises de Coliformes a $45^{\circ} \mathrm{C}$ e Staphylococcus coagulase positiva, já para a análise de Salmonella sp. em $25 \mathrm{~g}$ foi realizada de acordo com Silva et al. (2007). Todas as determinações foram realizadas em duplicata.

\subsection{Análise sensorial e índice de aceitabilidade}

A análise sensorial foi realizada no Laboratório de Análise Sensorial do Instituto Federal de Educação, Ciência e Tecnologia do Ceará (IFCE) Campus Sobral.

A etapa de recrutamento foi realizada com voluntários saudáveis, entre estudantes, professores e funcionários de ambos os sexos e ampla faixa etária. Para 
a avaliação sensorial, realizou-se o teste de aceitação, com 61 provadores não treinados, saudáveis (não gripado e resfriados) ou indispostos e/ou ter entrado em contato há menos de 1 hora com materiais e/ou alimentos de cheiro forte, escolhidos aleatoriamente.

A análise sensorial foi conduzida segundo o delineamento de blocos inteiramente casualizados (DIC). Foi empregado o teste de aceitabilidade, utilizando escala hedônica estruturada de 9 pontos, onde 1 (desgostei extremamente) e 9 (gostei extremamente), (MEILGAARD; CIVILLE; CARR, 2007). As amostras do salgadinho de frango sem glúten foram servidas em copos descartáveis, codificados com números de três dígitos. Os provadores receberam a amostra codificada com caneta e ficha para avaliação, de acordo com o (DIC), de forma individual em cabines apropriadas do laboratório de avaliação sensorial. Os atributos avaliados foram aparência, textura, sabor e aceitação global do produto.

Para avaliar a aceitação do salgadinho de frango sem glúten, foi calculado o índice de aceitabilidade (IA\%), sendo o mesmo considerado de boa aceitação quando o resultado de IA\% foi maior ou igual a $70 \%$, de acordo com a fórmula descrita por Bispo et al. (2004) na Equação 2:

$$
I A(\%)=(A / B) \times 100,
$$

onde: IA \%: Índice de aceitabilidade; A: Nota média obtida no atributo; B: Maior nota dada ao atributo.

\section{RESULTADOS E DISCUSSÃO}

Foi possível produzir um salgadinho típico da culinária brasileira denominado coxinha de frango substituindo a farinha de trigo tradicionalmente utilizada por farinha de arroz e batata com $100 \%$ de substituição. Normalmente os salgadinhos encontrados em estabelecimentos comerciais, formais (confeitarias, padarias, doce culturas) e/ou informais (confeiteiras, cozinheiras ou padeiros) são preparados com ingredientes como: (leite, batatas cozidas, margarina, farinha de trigo, farinha de rosca, ovos, extrato de tomates, cebolas, cheiroverde, pimentão, alho e corantes). Nessa fórmula há ingredientes como a farinha de trigo e farinha de rosca que o celíaco deve eliminar da sua dieta e o leite que concomitantemente alguns celíacos podem apresentar intolerância à lactose e devem também evitar esse ingrediente. Em virtude disso, foram escolhidos como substitutos da farinha de trigo com $100 \%$ de substituição a farinha de arroz e batata, e optou-se por uma formulação sem adição de leite.

\subsection{Análise físico-química}

Os valores de umidade do salgadinho de frango sem glúten (Tabela 3) foram inferiores aos de Ito (2003), que trabalhando com o desenvolvimento de uma Tabela Brasileira de Composição de Alimentos-USP: Banco de dados de alimentos industrializados (TBCA-USPBDAI), para referência, apresentou referências de dados de umidade para uma coxinha de frango de 49,64\% para as formulações padrão. Analisando resultados encontrados por Pessanha, Ferreira (2010) que trabalhando com a determinação de teores de lipídios totais e perfil de ácidos graxos em diversos "salgadinhos" obteve valor médio de umidade de $52,9 \%$ para coxinhas de frango. Observa-se que o salgadinho de frango sem glúten do presente trabalho diferencia-se dos trabalhos supracitados pelo baixo teor de umidade. Esse resultado é interessante pois alimentos com umidade menores apresentam maior estabilidade microbiológica. No entanto isto acarreta em um elevado valor de carboidratos totais.

Os carboidratos apresentaram valor médio de $42,37 \%$ no presente trabalho (Tabela 3), cujo resultado é superior ao de Ito (2003), que apresentou referências de dados para uma coxinha de frango de $29,2 \%$ de carboidrato.

O valor de carboidratos do salgadinho produzido no presente trabalho também foram superiores aos obtidos por Aguiar, Oliveira, Grassiolli (2011), que elaborando um Manual de Contagem de Carboidratos (MCC) para auxiliar no tratamento do diabetes e apresentou referências de dados do teor de carboidratos de uma coxinha de frango de $21 \%$, mesmo a porção avaliada (50g/unidade) ser $10 \mathrm{~g}$ a mais do que a do salgadinho do presente trabalho.

A recomendação de carboidrato varia entre 45 a $65 \%$ do valor energético total (VET), pela Dietary Reference Intakes (DRI's) por dia advindas da dieta, (para crianças acima de 4 anos e adultos $<50$ anos) (PHILIPPI, 2008). O principal papel dos carboidratos na dieta é promover energia para as células, especialmente do cérebro, que é o único órgão glicose dependente. A DRI estabelece cerca de $135 \mathrm{~g}$ por dia de carboidratos para adultos. O que caracteriza o salgadinho produzido nesse trabalho um alimentos com um alto teor de carboidratos, vindo a representar quase $50 \%$ da sua composição centesimal. Praticamente todo o carboidrato do salgadinho está presente na massa, então para diminuir essa quantidade pode ser elaborado um salgadinho com menos massa e mais recheio onde está praticamente toda a proteína do produto.

Os valores de proteína do salgadinho de frango sem 
DESENVOLVIMENTO, CARACTERIZAÇÃO E AVALIAÇÃO SENSORIAL DE SALGADINHO DE FRANGO SEM GLÚTEN

Tabela 3: Composição centesimal (média \pm desvio padrão) do salgadinho de frango sem glúten após fritura.

\begin{tabular}{|c|c|c|c|c|c|c|}
\hline \multirow{3}{*}{$\begin{array}{l}\text { Período } \\
\text { (dias) }\end{array}$} & \multicolumn{6}{|c|}{ Composição centesimal $(\%)^{*}$} \\
\hline & \multicolumn{6}{|c|}{ Análises } \\
\hline & Umidade & Lipídios & Cinzas & Proteínas & Carboidratos $^{1}$ & $\begin{array}{l}\text { Valor Calórico Total } \\
(\mathrm{kcal})^{2}\end{array}$ \\
\hline 1 & $38,02 \pm 1,36$ & $11,21 \pm 0,13$ & $1,24 \pm 0,02$ & $7,14 \pm 0,27$ & $42,37 \pm 1,27$ & 299,01 \\
\hline
\end{tabular}

(*)Resultados expressos em base úmida $\left(\%=\mathrm{g} .100 \mathrm{~g}^{-1}\right)$; média de três repetições \pm desvio padrão.; $\left(^{1}\right)$ Carboidratos por diferença.; $\left(^{2}\right)$ Resultado expresso em kcal $\left(\mathrm{g} .100 \mathrm{~g}^{-1}\right) /$ calculado pelos valores, média da composição.

Fonte: Autores.

glúten $(7,14 \%)$ foram mais baixos que os valores obtidos por Ito (2003), que obteve valores de $11,28 \%$ para uma coxinha de frango.

Consoante a recomendação das DRI's a Ingestão Diária Recomendada para Indivíduos por dia advindas da dieta, (para crianças acima de 4 anos e adultos $<50$ anos), recomenda-se lipídios de 20 a $35 \%$ do VET (valor energético total) e as proteínas de 10 a $15 \%$ do VET (PHILIPPI, 2008). Caracterizando o salgadinho do presente trabalho como um alimento de aporte calórico e protéico. Esses são importantes componentes nos alimentos e estão envolvidas na formação e manutenção das células e dos tecidos do corpo e dos órgãos. O arroz é o cereal com menor teor de proteínas (aproximadamente $7 \%$ ), sendo que estas ainda apresentam baixo valor biológico (SCHMIELE et al., 2013), o desenvolvimento de um salgadinho de frango sem glúten, com farinha de arroz torna-se ainda mais proeminente, pois neste alimento será acrescido, combinando as proteínas do arroz com as do frango, eliminando a carência por parte do teor de proteínas da farinha de arroz e seu baixo valor biológico.

Os valores apresentados para lipídios neste trabalho foram superiores ao trabalho de Ito (2003) e Pessanha; Ferreira (2010) que obtiveram respectivamente valores médios para lipídios de $7,77 \%$ e $7,6 \%$ para a coxinha de frango. O salgadinho de frango sem glúten do presente trabalho absorveu em média 3,38 g de óleo em sua porção (40 g) após o processo de fritura em óleo de soja, o que representa uma incorporação de lipídios de $75,45 \%$ em sua porção. O SFSG antes de ser submetido ao processo de fritura possuía em média apenas $1,1 \mathrm{~g}$ de lipídios em sua porção.

O valor calórico total ( $\mathrm{kcal}$ ) do SFSG do presente trabalho foi superior ao de Ito (2003) que apresentou como referência de dado de valor calórico total para uma coxinha de frango de $232 \mathrm{kcal} 100 \mathrm{~g}^{-1}$, valor esse inferior ao encontrado para o SFSG do presente trabalho. Pode-se justificar o alto valor calórico total do SFSG do presente trabalho devido ao seu baixo teor de umidade $(38,02 \%)$, em relação ao trabalho supracitado, resultando assim, em um maior teor de carboidratos $(42,37 \%)$ e consequentemente uma maior absorção de gordura pelo SFSG após fritura. Valores antagônicos também foram apresentados por Aguiar, Oliveira, Grassiolli (2011) que obteve valor de $187 \mathrm{kcal}$ na porção avaliada (50g/unidade) da coxinha de frango, apresentando aporte calórico superior ao do salgado de frango sem glúten do presente trabalho. O SFSG do presente trabalho apresentou aporte calórico com um valor médio de $299,01 \mathrm{kcal}\left(\mathrm{g} .100 \mathrm{~g}^{-1}\right)$, apresentando na porção (40 g) um total de 119,60 kcal.

Coregio (2009) trabalhando com o desenvolvimento de uma coxinha de frango e outros receitas para festas para pessoas com doença celíaca e intolerantes à lactose, obteve valores médios de 180,20 kcal (g.100g $\mathrm{g}^{-1}$ ); 9,81 de proteína; $14,06 \%$ de lipídio; $21,25 \%$ carboidrato, para a sua coxinha de frango sem glúten. Isso pode está relacionado aos diferentes ingredientes utilizados na receita (aipim cozido, creme de arroz, margarina, ovo, tomate, cebola, tempero verde e frango) e principalmente dos ingredientes substitutos da farinha de trigo (aipim cozido, creme de arroz) adicionados serem diferentes do presente trabalho e utilizados em proporções diferentes $(26,17 \% ; 16,49 \% ; 5,49 \%$; $6,02 \% ; 8,11 \% ; 9,42 \% ; 1,30 \%$; e $26,96 \%$ ), respectivamente. A proporção dos ingredientes substitutos da farinha de trigo (aipim cozido, creme de arroz) represen$\operatorname{tam} 42,67 \%$ da receita da coxinha de frango, esses valores diferem das proporções utilizadas para o salgadinho de frango sem glúten do presente trabalho para os ingredientes substitutos da farinha de trigo (farinha de arroz e batata inglesa) que representam apenas $23,12 \%$ da formulação. Ainda a formulação da coxinha de frango difere do salgadinho do presente trabalho por adicionar ovo na receita $(6,02 \%)$.

O salgadinho de frango sem glúten do presente trabalho, apresentou valores médio de cinzas de $1,24 \%$, valor esse, inferior a coxinha de frango relatada por Ito (2003) que obteve valor de $2,11 \%$ para cinzas. 


\subsection{Análise microbiológica}

A qualidade microbiológica do SFSG (Tabela 4) do presente trabalho, se encontra em conformidade com os padrões exigidos pela legislação brasileira (ANVISA, 2001).

Tabela 4: Determinação de microrganismos indicadores de contaminação no salgadinho de frango sem glúten após fritura.

\begin{tabular}{ccc}
\hline $\begin{array}{c}\text { Parâmetros } \\
\text { Microbiológicos }\end{array}$ & $\begin{array}{c}\text { Período } \\
\text { (Dias) }\end{array}$ & $\begin{array}{c}\text { Limites } \\
\text { ANVISA,2001 }\end{array}$ \\
\hline $\begin{array}{c}\text { Coliformes a } 45^{\circ} \mathrm{C} \\
\left(\text { NMP.g }^{-1}\right)^{*}\end{array}$ & Ausência & $10^{2}$ \\
\hline $\begin{array}{c}\left.\text { S. } \text { aureus }^{(\text {NMP.g }}{ }^{-1}\right)^{*} \\
\text { Salmonella } \text { sp }\end{array}$ & Ausência & Ausência \\
\hline \multicolumn{3}{c}{ (*)Determinações realizadas em duplicata. } \\
Fonte: Autores.
\end{tabular}

A ausência de contaminação está relacionada com a qualidade do produto, visto que foram processados em condições adequadas e foram mantidos em condições ideais de armazenamento, também existe a contribuição do processo de fritura, garantindo assim, a qualidade microbiológica do produto e preservando a saúde do consumidor.

As Boas Práticas de Fabricação (BPF) garantem que o produto final seja seguro para consumo pelo consumidor e reduzem os possíveis riscos de contaminação por microrganismos deterioradores e patógenos durante a vida de prateleira do produto.

\subsection{Análise sensorial e índice de aceitabilidade}

Pode-se observar que o salgadinho de frango sem glúten teve uma boa aceitação, visto que obtiveram para os atributos sabor, textura e aceitação global, respectivamente as médias 7,$64 ; 7,64 ; 7,56$. $\mathrm{O}$ atributo com menor média foi a aparência, com 7,41. O salgadinho de frango sem glúten teve uma boa aceitabilidade, visto que para todos os atributos avaliados a coxinha apresentou aceitação superior a 7,41, que corresponde as expressões na escala de avaliação sensorial (gostei - gostei extremamente). Cujo o único ponto negativo atribuído pelos provadores ao produto, foi pouco sal. Houve ainda alto índice de aceitabilidade do produto $(94,5 \%)$. Os resultados da aceitação dos atributos sensoriais avaliados e do índice de aceitabilidade estão esboçados na Tabela 5 .

$\mathrm{O}$ atributo com menor média foi a aparência com
Tabela 5: Resultados da análise sensorial do salgadinho de frango sem glúten e índice de aceitabilidade

\begin{tabular}{ccccc}
\hline Aparência & Sabor & Textura & $\begin{array}{c}\text { Aceitação } \\
\text { global }\end{array}$ & IA (\%)* \\
\hline 7,41 & 7,64 & 7,64 & 7,56 & 94,5 \\
\hline
\end{tabular}

(*) Resultados expressos com base na impressão global.

Fonte: Autores.

7,41 , isso, se deve a ele ter sido o atributo que mais recebeu notas inferiores a 6 , consequentemente baixando a sua média, como pode ser visualizado nos histogramas de frequência das notas da aceitação dos atributos (Figura 2).

Figura 2: Histograma de frequência das notas da aceitação da aparência do salgadinho de frango sem glúten; (B) Histograma de frequência das notas da aceitação do sabor do salgadinho de frango sem glúten; (C) Histograma de frequência das notas da aceitação da textura do salgadinho de frango sem glúten; (D) Histograma de frequência das notas da aceitação global do salgadinho de frango sem glúten, em relação à frequência dos valores hedônicos atribuídos, onde 1 (desgostei extremamente) e 9 (gostei extremamente).
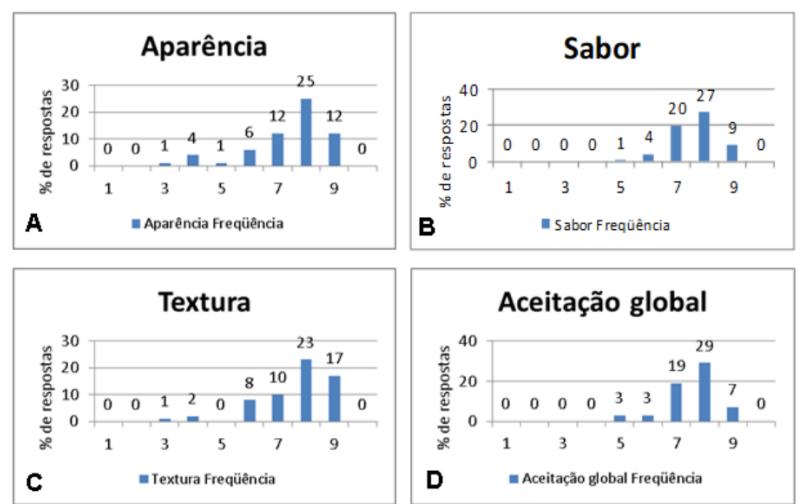

Fonte: Autores

De acordo com Sabbatini et al. (2011) para que um produto seja considerado como aceito, em termos de suas propriedades sensoriais, é necessário que obtenha um índice de aceitabilidade (IA) de no mínimo $70 \%$ e, neste caso, o salgadinho de frango sem glúten obteve aceitabilidade bastante superior, em relação a todos os atributos avaliados (Aparência, sabor, textura e aceitação global), apresentando respectivamente 92,6\%; 95,5\%; 95,5\% e 94,5\% de (IA). Dessa forma, o salgadinho de frango sem glúten foi aprovada pelos consumidores. $\mathrm{O}$ índice de aceitabilidade alto de 94,5\% para o salgadinho de frango sem glúten pode ser compreendido visualizado os histogramas de frequência das notas da aceitação dos atributos (Figura 2) (aparência, sabor, textura e aceitação global), respectiva- 
DESENVOLVIMENTO, CARACTERIZAÇÃO E AVALIAÇÃO SENSORIAL DE SALGADINHO DE FRANGO SEM GLÚTEN

mente, onde de maneira que a maioria dos provadores cerca de $40,98 \% ; 44,26 \% ; 37,70 \% ; 47,54 \%$, e $19,67 \%$; $14,75 \% ; 27,86 \% ; 11,47 \%$, respectivamente, atribuíram notas 8 e 9 na escala hedônica de avaliação sensorial para o salgadinho de frango sem glúten do presente trabalho. Esses percentuais altos de notas atribuídas 8 e 9 para o SFSG foi determinante para o seu elevado (IA).

Santos et al. (2014) trabalhando com desenvolvimento de salgado de frango isento de glúten a base de biomassa de banana verde e enriquecido com vitamina A, obteve um alto índice de aceitabilidade do produto, $(88,8 \%)$, e intenção positiva de compra de $84,01 \%$. O presente trabalho obteve resultados mais promissores, superiores de aceitabilidade de 94,5\%.

Trabalhando com o desenvolvimento de uma coxinha de frango para pessoas com doença celíaca e intolerantes à lactose Coregio (2009) obteve porcentagem de aceitação maior que o salgadinho de frango sem glúten do presente trabalho, com aprovação pelos provadores de $100 \%$.

No entanto na formulação de Coregio foi utilizado aipim cozido, creme de arroz, margarina, ovo, tomate, cebola, tempero verde e frango diferente da formulação utilizada neste trabalho onde a substituição da farinha de trigo foi feita por farinha de arroz e batatas.

\section{CONCLUSÕES}

A formulação do salgadinho de frango sem glúten substituindo a farinha de trigo por farinha de arroz e batatas foi aprovada sensorialmente, obtendo alto índice de aceitação do produto constituindo-se uma alternativa de diversificação de preparação para indivíduos celíacos.

\section{AGRADECIMENTOS}

Os autores agradecem pelo apoio financeiro à FUNCAP/IFCE-Campus Sobral.

\section{REFERÊNCIAS}

ACELBRA. Associação dos celíacos do Brasil 2015. Disponível em: <http://www.acelbra.org.b $>$.

AGUIAR, A. C. B.; OLIVEIRA, H. S. D.; GRASSIOLLI, S. M. Porto Alegre. ICD, 52 p, 2011. Disponível em: <http://www.icdrs.org.br/arquivos/pdf/ Manual-Contagem-Carboidratos.pdf $>$

AGUIAR, E. A. R.; SOUZA, V. R. S. Elaboração e análise sensorial de cookie de castanha de caju sem glúten a base de farinha de amaranto. Revista
Interdisciplinar do Pensamento Científico, v. 1, n. 1, p. 52-64, 2015.

ALMEIDA, S. G.; SÁ, W. A. C. Amaranto (amaranthus ssp) e quinoa (chenopodium quinoa) alimentos alternativos para doentes celíacos. Ensaios e Ciência: Ciências Biológicas, Agrárias e da Saúde, v. 13, n. 1, p. 77-92, 2009.

ANVISA. Agência Nacional de Vigilancia Saniária Resolução n.12, de 02 de janeiro de 2001. Aprova o Regulamento Técnico sobre Padrões Microbiológicos para Alimentos. Disponível em: <ttp://portal.anvisa.gov.br/wps/wcm/connect/ a47bab8047458b909541d53fbc4c635/RDC_12_2001. pdf?MOD=AJPERES $>$

\section{ANVISA. AGÊNCIA NACIONAL DE}

VIGILANCIA SANITÁRIA. Resolução RDC n.359, de 23 de dezembro de 2003. 2003. Aprova o Regulamento Técnico de Porções de Alimentos Embalados para Fins de Rotulagem Nutricional.

ARAÚJO, A. C. M.; MARQUES, M. P.; SANTOS, G. F. Cookies à base de farinha de pupunha integral: valor nutricional e aceitabilidade. In: III Congresso Internacional de Nutrição Especializada-COINE. Anais 2014,, 2014. ISSN Rio de Janeiro, 2014. Disponível em:. Acesso em: 21 Dez. 2015. Disponível em: <http://www.riosemgluten.com/Anais_do_III_ COINE_2014.pdf $>$

BISPO, E.; SANTANA, L. R. R.; CARVALHO, R. D. S.; LEITE, C. C.; LIMA, M. A. C. Processamento, estabilidade e aceitabilidade de marinado de vôngole (anomalocardia brasiliana (gmelin, 1791)). Ciência e Tecnologia de Alimentos, Campinas, v. 24, n. 3, p. 353-356, 2004.

BRASIL. Diário Oficial da República Federativa do Brasil. 2003. Ministério da Agricultura, Pecuária e Abastecimento. Instrução Normativa $n^{\circ}$ 62, de 26 de agosto de 2003. Oficializa os Métodos Analíticos Oficiais para Análises Microbiológicas para Controle de Produtos de Origem Animal e Água. Seção 1, p. 14.

BRASIL; LUTZ, I. A. Métodos físico-químicos para análise de alimentos. 2005. 4.ed. Brasília: Ministério da Saúde. P. 1018.

COREGIO, D. F. V. Elaboração e aceitabilidade de receitas para festas de aniversário para um grupo de pessoas portadoras de doença celíaca e/ou intolerância à lactose no município de criciúma, s c. Trabalho de 
DESENVOLVIMENTO, CARACTERIZAÇÃO E AVALIAÇÃO SENSORIAL DE SALGADINHO DE FRANGO SEM GLÚTEN

conclusão de curso para graduação em Nutrição - Universidade do extremo sul catarinense., p. 69, 2009. ISSN Criciuma.

EGASHIRA, E. M.; ALMEIDA, O. F.; BARBIERI, D.; KADA, Y. K. L. O celíaco e a dieta: Problemas de adaptação e alimentos alternativos. Jornal de Pediatria., v. 8, p. 41-44, 1986.

FERREIRA, S. M. R.; LUPARELLI, P. C.; SCHIEFERDECKER, M. E. M.; VILELA, R. M. Cookies sem glúten a partir da farinha de sorgo. Archivos Latino Americanos de Nutrição, v. 59, n. 4, p. 443-440, 2009.

ITO, M. S. B. Tabela brasileira de composição de alimentos - usp: Banco de dados de alimentos industrializados. Dissertação de Mestrado Faculdade de Ciência dos Alimentos - Universidade de São Paulo., 2003. São Paulo, 2003. 218 f.

KADAN, R. S.; ROBINSON, M.; THIBODEAUX D.P.; PEPPERMAN JR, A. Texture and other physicochemical properties of whole rice bread. Journal Food Science, v. 66, n. 7, p. 940-944, 2001. Disponível em: <http: //dx.doi.org/10.1111/j.1365-2621.2001.tb08216.x>

KADAN, R. S.; ZIELGLER, G. M. Role of ingredients in the texture of flan-like food. Cereal Chemistry, v. 66, n. 3, p. 161-165., 1989.

KIRINUS, P.; COPETTI C.; OLIVEIRA, V. R. Utilização de farinha de soja (glycine max) e de quinoa (chenopodium quinoa) no preparo de macarrão caseiro sem glúten. Alimentos Nutrição, v. 21, n. 4, p. 555-561, 2010. ISSN Araraquara.

KOTZE, L. M. S. Doença celíaca. Jornal Brasileiro de Gastroenterologia, v. 6, n. 1, p. 23-34, 2006. ISSN Rio de Janeiro.

MACêDO, P. M. S.; MADRONA, G. S.; SCAPIM, M. R. S.; CESTARI, L. A. Avaliação físico-química e sensorial de biscoito salgado isento de glúten contendo de farinha de linhaça. Revista Tecnológica, Maringá, v. 23, p. 33-40, 2014.

MCCUE, N. Clean labels with rice. Prepared Foods, v. 166, p. 57, 1997.

MEILGARARD, M.; CIVILLI, G.; CARR, B. 3.ed. boca raton: Crc press. Sensory evaluation techniques., 2007.
MONTEIRO, S. Z. Utilização de mesclas de farinhas de arroz, inhame e quinoa na elaboração de disco de pizza pré assado sem glúten e sem lactose.

Trabalho de Conclusão de Curso (TCC) - Curso de Engenheiro de Alimentos, Universidade Federal do Rio Grande do Sul, Porto Alegre, 2013, 2013. 2013. $82 \mathrm{f}$.

NUNES, A.; FARIA, A.; STEINMACHER, F.; VIEIRA, J. Processos enzimáticos e biológicos na panificação. Florianópolis. Universidade Federal de Santa Catarina - UFSC, p. 2-5, 2006.

OLIVEIRA, R. N.; MARQUES, M. P. Biscoitos cookies produzidos com farinha de fruta-pão (artocarpus altilis) variedade semífera como alternativa para pacientes celíacos: análise nutricional e sensorial. In: III Congresso Internacional de Nutrição Especializada-COINE. Anais 2014, 2014. ISSN Rio de Janeiro, 2014. Disponível em:. Acesso em: 21 Dez. 2015. Disponível em: <http://www.riosemgluten.com/ Anais_do_III_COINE_2014.pdf>

PAIM, V.; SCHUCK, C. O custo da alimentação sem glúten no brasil. Revista Vida sem Glúten e sem Alergias, 2010. ISSN São Paulo, jan. 2010. Disponivel em:. Acesso em: 20 Dez. 2015. Disponível em: <http://www.vidasemglutenealergias.com/ o-custo-da-alimentacao-sem-gluten-no-brasil/609/>

PEREIRA, B. S.; CARDOSO, E. S.; MENDOçA, J. O. B.; SOUZA, L. B.; SANTOS M. P.; ZAGO, L.; FREIRAS, S. M. L. Análise físico química e sensorial do pão de batata isento de glúten enriquecido com farinha de chia. Demetra: alimentação, nutrição \& saúde, v. 8, n. 2, p. 125-136, 2013.

PESSANHA, T. M. T.; FERREIRA, K. S. Lipídios totais e perfil de ácidos graxos de "salgadinhos" comercializados em campos dos goytacazes, rj. Alimentos e Nutrição. Araraquara, v. 21, n. 3, p. 357-365, 2010.

PHLIPPI, S. T. Pirâmide dos alimentos: fundamentos básicos da nutrição. [S.1.], 2008.

ROSELL, C. M.; MARCO, C. Gluten-free cereal products and beverages. In: ARENDT, E. K.; BELLO, F. D. Rice. 1. ed. Oxford: Elsevier, n. Cap 4, p. 81-100, 2008.

SABATINI, D. R.; SILVA, K. M.; PICININ, M. E.; SANTO V. R.; SOUZA, G. B. P. C. A. M. D.

Composição centesimal e mineral da alfarroba em pó 
DESENVOLVIMENTO, CARACTERIZAÇÃO E AVALIAÇÃO SENSORIAL DE SALGADINHO DE FRANGO SEM GLÚTEN

e sua utilização na elaboração e aceitabilidade em sorvete. Revista Alimentos e Nutrição, v. 22, n. 1, p. 129-36, 2011.

SANTOS, B.; FRANçA, I.; SILVA A.; SILVA, T.; VIANA, K.; ONO-SILVA, Y. Aceitabilidade de salgado de frango isento de glúten desenvolvido com biomassa de banana verde e enriquecido com vitamina a. n: III Congresso Internacional de Nutrição Especializada-COINE. Anais 2014, Rio de Janeiro, 2014. Acesso em: 21 Dez. 2015b. Disponível em: <http://www.riosemgluten.com/Anais_do_III_ COINE_2014.pdf $>$.

SANTOS, S.; SOUSA, M.; PREREIRA, H.; SERRA, G.; FERREIRA, P.; VIANA, K.; ONO-SILVA, Y. Aceitabilidade de pão de forma isento de glúten e lactose preparado com biomassa do feijão branco (phaseolus vulgaris). In: III Congresso Internacional de Nutrição Especializada-COINE. Anais 2014, Rio de Janeiro, 2014. Acesso em: 21 Dez. 2015a. Disponível em: <http://www.riosemgluten.com/Anais_ do_III_COINE_2014.pdf>

SCHMIELE, M.; JAEKEL, L. Z.; ISHIDA, P. M. G.; CHANG, Y. K.; STEEL, C. J. Massa alimentícia sem glúten com elevado teor proteico obtida por processo convencional. Ciência Rural, Santa Maria, v. 43, n. 5, p. 908-914, 2013.

SDEPANIAN, V. L.; SCALETSKY, I. C. A.; MORAIS, M. B.; FAGUNDES-NETO, U. Pesquisa de gliadina em medicamentos-informação relevante para a orientação de pacientes com doença celíaca. Arq Gastroenterol, v. 38, n. 3, p. 176-182, 2001.

SEVERO, M. G.; MORAES K.; RUIZ, W. A. Modificação enzimática da farinha de arroz visando à produção de amido resistente. Química Nova, v. 33, n. 2, p. 345-350, 2010. Acesso em: 14 out. 2015. Disponível em: <http: //dx.doi.org/10.1590/S0100-40422010000200021>

SILVA, B. C.; CARPENEDO, E.; SILVA, L. O.; LAVINAS, F. C.; RIBEIRO-ALVES, M. A. Elaboração de cupcake de alfarroba isento de glúten. Almanaque Multidisciplinar de Pesquisa, v. 1, n. 1, 2014.

SILVA, N.; JUNQUEIRA, V. C. A.; SILVEIRA, E. F. A.; TANIWAKI, M. H.; SANTOS, R. F. S.; GOMES, R. A. R. Manual de métodos de análises microbiológica de alimentos. [S.1.], 2007. 552p.
VIEIRA, C. R. Extração enzimática das proteínas da farinha de arroz. Ciência e Tecnologia de Alimentos, v. 28., n. 3, p. 599-606, 2008. Disponível em:. Disponível em: <http: //dx.doi.org/10.1590/S0101-20612008000300015>

WOLFF, C. H.; SEGAL, F.; WOLFF, F. Artigo 148. Abc da Saúde, Doença Celíaca, 2015. Disponível em:. Disponível em: <https://www.abcdasaude.com. br/gastroenterologia/doenca-celiaca $>$

ZANDONADI, R. P. Massa de banana verde: uma alternativa para exclusão do glúten. 106 f. Tese de Doutorado/Programa de Pós-Graduação em ciência da saúde da Universidade de Brasília, DF, 2009. 